\section{JTI}

JOURNAL OF

TRAUMA AND INJURY

Received: March 25, 2020

Accepted: March 25, 2020

\section{Correspondence to}

Gil Jae Lee, M.D., Ph.D.

Department of Traumatology, Gachon University College of Medicine, Gachon University Gil Medical Center, $21 \mathrm{Nam}$ dong-daero 774beon-gil, Namdong-gu, Incheon 21565, Korea

Tel: +82-32-460-3010

Fax: +82-32-460-2372

E-mail:nonajugi@gilhospital.com

*PYJ and BCY contributed equally as first authors.

\title{
Clinical Practice Guideline for the Treat- ment of Traumatic Shock Patients from the Korean Society of Traumatology
}

Pil Young Jung, M.D., Ph.D., ${ }^{1 *}$, Byungchul Yu, M.D., ${ }^{2 *}$, Chan-Yong Park, M.D., Ph.D., Sung Wook Chang, M.D. , O Hyun Kim, M.D., Ph.D. ${ }^{5}$, Maru Kim, M.D., Ph.D. ${ }^{6}$, Junsik Kwon, M.D. , Gil Jae Lee, M.D., Ph.D. ${ }^{2}$, Korean Society of Traumatology (KST) Clinical Research Group

${ }^{1}$ Department of Surgery, Wonju Severance Christian Hospital, Yonsei University Wonju College of Medicine, Wonju, Korea

${ }^{2}$ Department of Traumatology, Gachon University College of Medicine, Gachon University Gil Medical Center, Incheon, Korea

${ }^{3}$ Department of Trauma Surgery, Wonkwang University Hospital, Iksan, Korea

${ }^{4}$ Department of Thoracic and Cardiovascular Surgery, Trauma Center, Dankook University Hospital, Cheonan, Korea

${ }^{5}$ Department of Emergency Medicine, Wonju College of Medicine, Yonsei University, Wonju, Korea

${ }^{6}$ Department of Trauma Surgery, Uijeongbu St. Mary's Hospital, College of Medicine, The Catholic University of Korea, Uijeongbu, Korea

${ }^{7}$ Division of Trauma Surgery, Department of Surgery, Ajou University School of Medicine, Suwon, Korea

Purpose: Despite recent developments in the management of trauma patients in South Korea, a standardized system and guideline for trauma treatment are absent.

Methods: Five guidelines were assessed using the Appraisal of Guidelines for Research and Evaluation II instrument.

Results: Restrictive volume replacement must be used for patients experiencing shock from trauma until hemostasis is achieved (1B). The target systolic pressure for fluid resuscitation should be 80-90 $\mathrm{mmHg}$ in hypovolemic shock patients (1C). For patients with head trauma, the target pressure for fluid resuscitation should be $100-110 \mathrm{mmHg}(2 \mathrm{C})$. Isotonic crystalloid fluid is recommended for initially treating traumatic hypovolemic shock patients $(1 \mathrm{~A})$. Hypothermia should be prevented in patients with severe trauma, and if hypothermia occurs, the body temperature should be increased without delay (1B). Acidemia must be corrected with an appropriate means of treatment for hypovolemic trauma patients (1B). When a large amount of transfusion is required for trauma patients in hypovolemic shock, a massive transfusion protocol (MTP) should be used (1B). The decision to implement MTP should be made based on hemodynamic status and initial responses to fluid resuscitation, not only the patient's initial condition (1B). The ratio of plasma to red blood cell concentration should be at least 1:2 for trauma patients requiring massive transfusion (1B). When a trauma patient is in life-threatening hypovolemic shock, vasopressors can be administered in addition to fluids and blood products (1B). Early administration of tranexamic acid is recommended in trauma patients who are actively bleeding or at high risk of hemorrhage (1B). For hypovolemic patients with coagulopathy non-responsive to primary therapy, the use of fibrinogen concentrate, cryoprecipitate, or recombinant factor VIIa can be considered (2C).

Conclusions: This research presents Korea's first clinical practice guideline for patients with traumatic shock. This guideline will be revised with updated research every 5 years.

Keywords: Shock, Traumatic; Practice guideline; Wounds and injuries 


\section{INTRODUCTION}

Trauma is the third leading cause of death among all ages, and it is the leading cause of death in people under the age of 45 in Korea [1]. The preventable death rate in Korea is significantly higher than in well-established nations with major trauma centers. To overcome this problem, the Korean government has been implementing a trauma center model since 2012, and 17 trauma centers have been established and funded across the nation. Despite recent developments in managing trauma patients in South Korea, a standardized system and guideline for trauma treatment are absent.

A major trauma patient is defined as a severely injured patient with associated injuries from trauma with an Injury Severity Score (ISS) greater than 15. Uncontrolled bleeding is the leading cause of potentially preventable death $[2,3]$. Massive bleeding causes acidosis and coagulopathy, leading to multiple organ failure and death [4-8]. Time from transport to the surgery bed and efficient treatment plans play a key role in reducing preventable deaths and improving prognosis. Studies have provided evidence that early surgery in patients with hemorrhagic shock may lower mortality $[9,10]$.

Clinical practice guidelines are systematically developed to help physicians and patients to make decisions in specialized circumstances. The need for such medical guidelines has risen concomitantly with improvements in the quality of medical care in the past 20 years. Medical guidelines efficiently provide treatment options. This is particularly true in cases of polytrauma, where multiple medical specialties are involved, meaning that medical guidelines can help avoid inefficient, dangerous, and time-consuming procedures. This approach allows a diverse pool of physicians from different medical specialties to communicate using a common and agreed-upon framework of rules for treating patients, which acts as a compass for appropriate treatments. It would be appropriate for South Korea to adapt established guidelines for its specific needs and infrastructure in order to reach the level of competence of more experienced trauma systems around the globe.

The goal of this study was to create the basis of a clinical practice guideline to be used as the backbone for other surgeons to inspect and suggest improved guidelines for trauma patients. Here, we would like to provide guidelines for the initial treatment of traumatic shock patients.

\section{METHODS}

\section{Developing the medical guideline}

Multiple published guidelines from foreign countries were compiled, selected, and adapted to the circumstances of the Korean healthcare system. The compiled data on recommendations were either used in the guideline as is, or the international clinical guidelines were adapted through a systematic process. For some aspects of treatment, decisions were made to incorporate new material that is relevant to trauma. Although the treatment guidelines were selected through a hybrid method of adapting extant guidelines and developing new guidelines, the core questions of the guidelines consist of questions adapted from other medical trauma guidelines. The development process of the guideline consisted of the following steps: the selection of developers of the trauma guideline, the stepby-step tasks of the adaptation and development process, and a review of the grading system for the strength of recommendations for specific treatments.

\section{Selection and composition of the trauma guideline}

To create a standardized treatment guideline for trauma, a committee board was selected. The board members were recommended by the Korean Society of Traumatology for the following roles: one research methodology expert and a group of board members for planning, developing, researching, adapting, sorting, reviewing and overall decision-making throughout the whole process. The research methodology expert served as an advisory board member for overseeing the development process and consulting regarding the dissemination and execution of the plans. The committee of 17 experts in their fields was instructed to plan, develop, and collect feedback on a draft of the guideline. This consisted of choosing the appropriate core questions and keywords, selecting and adapting which guidelines to use, and writing the first draft by recommending and summarizing information from other sources (Table 1). During the development of the guide- 
line, 19 advisory members were selected by the chief surgeon of Korea's trauma centers and by the Korean Society of Traumatology for review and further advisory input.

\section{Adapting a standardized treatment guideline for trau- ma}

To develop the trauma guideline, the committee members initially discussed the scope of material that the guideline should cover by considering treatment plans ranging from the time of the patient's arrival to diagnosis and discharge. The core questions were then written through the PICO process. Due to the nature of trauma patients, satisfactory questions for the intervention and comparison components of the PICO process could not be identified, which stimulated a discussion among the committee members to develop core questions. After these decisions, the first draft of the core questions was finalized, and the working committee examined the questions and wrote the second draft. This second draft was then re-examined by the core question committee and revised to generate the final draft. In the final draft, it was concluded by both the development and working committee that the PICO process could not be implemented as part of the final guideline.

\section{Searching medical guidelines}

Because published guidelines were not present inKore-

Table 1. Results of the quality assessment of previous guidelines

\begin{tabular}{|lcc|}
\hline Guideline & AGREE II score & Decision \\
\hline $\begin{array}{l}\text { EAST trauma practice manage- } \\
\text { ment guidelines }\end{array}$ & 83 & Recommended \\
NSW adult trauma clinical prac- & 60 & Recommended \\
tice guidelines & & \\
AHA CPR \& ECC guidelines & 97 & Recommended \\
$\begin{array}{l}\text { S3-guideline on treatment of } \\
\text { patients with severe and mul- } \\
\text { tiple injuries }\end{array}$ & 77 & Recommended \\
NICE & 90 & Recommended \\
\hline
\end{tabular}

No recommendation: AGREE $\|<50$.

EAST: Eastern Association for the Surgery of Trauma, NSW: New South Wales, AHA: American Heart Association, CPR: cardio-pulmonary resuscitation, ECC: emergency cardiovascular care, NICE: National Guideline Clearinghouse. an databases, other databases such as Ovid-MEDLINE, Ovid-EMBASE, and the National Guideline Clearinghouse were used to search for medical guidelines. The words, "trauma, severe trauma, initial management, guideline, resuscitation, hypovolemic shock, initial management" were selected as search terms for finding medical guidelines. The results were reviewed by the development committee and evaluated by the working committee.

\section{Writing the initial draft for advisory input on the level of evidence and grade of recommendation}

The working committee summarized the evidence regarding the core questions and evaluated the relevance and applicability of treatment in the Korean medical setting. The answer to each core question was summarized using published guidelines, and the committee members evaluated whether new research had been done after the guideline's publication date. After the working committee had answered and evaluated each core question, the development committee approved the final decision. After the decision, the working committee investigated the level of evidence and grade of recommendation and wrote the first draft.

The level of evidence and grade of recommendation were used in a modified version of the GRADE process. Although the core questions can be divided into four categories of level of evidence-"high, A," "moderate,

\section{Table 2. Strength of recommendations and quality of} evidence

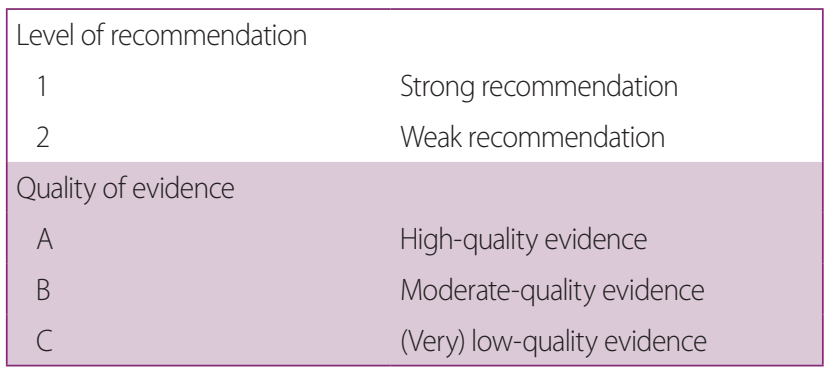

No recommendation: AGREE $\|<50$.

EAST: Eastern Association for the Surgery of Trauma, NSW: New South Wales, AHA: American Heart Association, CPR: cardio-pulmonary resuscitation, ECC: emergency cardiovascular care, NICE: National Guideline Clearinghouse. 


\section{JTI}

B," "low, C," and "very low, D"-in this guideline, only the first three were designated for use when writing the guideline. The grade of recommendation in the GRADE process can be divided into four categories based on the two dichotomies of "for and against" and "strong and weak." However, this guideline does not contain the "against" category, and instead only classifies the "for" category into "strong" and "weak" (Table 2). The words "recommend" and "advice" were used to describe strong recommendations, whereas words like "propose," "con-

Table 3. Scores from the Delphi technique (Likert scale 1-9)

\begin{tabular}{|c|c|c|c|}
\hline Key question & Recommendation & Mean & SD \\
\hline \multirow{3}{*}{$\begin{array}{l}\text { 1. Does maintaining a low target blood } \\
\text { pressure during initial fluid resuscita- } \\
\text { tion (I) improve the prognosis }(\mathrm{O}) \text { of } \\
\text { trauma-induced hypovolemic shock } \\
\text { patients }(\mathrm{P}) \text { ? }\end{array}$} & $\begin{array}{l}\text { A. Restrictive volume replacement must be used for patients experiencing shock } \\
\text { from trauma until hemostasis is achieved (1B). }\end{array}$ & 7.1 & 1.9 \\
\hline & $\begin{array}{l}\text { B. The target systolic pressure for fluid resuscitation should be } 80-90 \mathrm{mmHg} \text { in } \\
\text { hypovolemic shock patients (1C). }\end{array}$ & 7.2 & 1.5 \\
\hline & $\begin{array}{l}\text { C. For patients with head trauma, the target systolic pressure for fluid resuscitation } \\
\text { should be 100-110 mmHg in hypovolemic shock patients (2C). }\end{array}$ & 8.2 & 0.6 \\
\hline $\begin{array}{l}\text { 2. Which type of fluid }(I) \text { is appropriate } \\
\text { for the initial treatment }(\mathrm{O}) \text { of trau- } \\
\text { matic hypovolemic shock patients } \\
(\mathrm{P}) \text { ? }\end{array}$ & $\begin{array}{l}\text { A. Isotonic crystalloid fluid is recommended for initially treating traumatic hypovo- } \\
\text { lemic shock patients }(1 A) \text {. }\end{array}$ & 8.5 & 0.9 \\
\hline $\begin{array}{l}\text { 3. Will raising the temperature of a } \\
\text { hypothermic patient }(I) \text { improve the } \\
\text { survival outcomes }(O) \text { of trauma pa- } \\
\text { tients with hypovolemic shock }(P) \text { ? }\end{array}$ & $\begin{array}{l}\text { A. Hypothermia should be prevented in patients with severe trauma, and if hypo- } \\
\text { thermia occurs, the body temperature should be increased without delay (1B). }\end{array}$ & 8.8 & 0.4 \\
\hline $\begin{array}{l}\text { 4. What is the appropriate treatment } \\
\text { for acidemia }(I) \text { in trauma patients } \\
\text { with hypovolemic shock }(P) \text { ? }\end{array}$ & $\begin{array}{l}\text { A. Acidemia must be corrected with an appropriate means of treatment for hypo- } \\
\text { volemic trauma patients (1B). }\end{array}$ & 8.4 & 1.3 \\
\hline \multirow{2}{*}{$\begin{array}{l}\text { 5. What is the MTP }(I) \text { in trauma pa- } \\
\text { tients with hypovolemic shock }(P) \text { ? }\end{array}$} & \multirow{2}{*}{$\begin{array}{l}\text { A. When a large amount of transfusion is required for trauma patients in hypovo- } \\
\text { lemic shock, a massive transfusion protocol should be used (1B). } \\
\text { B. The decision to implement MTP should be made based on hemodynamic sta- } \\
\text { tus and initial responses to fluid resuscitation, not only the patient's initial condi- } \\
\text { tion (1B). }\end{array}$} & 8.5 & 0.7 \\
\hline & & 8.5 & 0.7 \\
\hline $\begin{array}{l}\text { 6. What ratio of concentrated red } \\
\text { blood cells to fresh frozen plasma } \\
\text { should be used for massive trans- } \\
\text { fusion (I) in traumatic hypovolemic } \\
\text { shock patients (P)? }\end{array}$ & $\begin{array}{l}\text { A. The ratio of plasma to red blood cell concentration should be at least 1:2 for } \\
\text { trauma patients requiring massive transfusion (1B). }\end{array}$ & 7.6 & 1.1 \\
\hline $\begin{array}{l}\text { 7. What are the criteria for adminis- } \\
\text { tering vasopressors }(I) \text { in trauma } \\
\text { patients with hypovolemic shock (P)? }\end{array}$ & $\begin{array}{l}\text { A. When a trauma patient is in life-threatening hypovolemic shock, vasopressors } \\
\text { can be administered in addition to fluids and blood products (1B). }\end{array}$ & 7.5 & 2.2 \\
\hline $\begin{array}{l}\text { 8. Does the administration of } \\
\text { tranexamic acid (I) help hemostasis } \\
(\mathrm{O}) \text { in trauma patients with hypovo- } \\
\text { lemic shock (P)? }\end{array}$ & $\begin{array}{l}\text { A. Early administration of tranexamic acid is recommended in trauma patients } \\
\text { who are actively bleeding or at high risk of hemorrhage (1B). }\end{array}$ & 7.8 & 1.1 \\
\hline $\begin{array}{l}\text { 9. Other than blood products }(\mathrm{C}) \text {, what } \\
\text { other therapies }(\mathrm{I}) \text { can be used in } \\
\text { hypovolemic shock patients with } \\
\text { traumatic coagulopathy }(\mathrm{P}) \text { ? }\end{array}$ & $\begin{array}{l}\text { A. For traumatic hypovolemic patients with coagulopathy non-responsive to pri- } \\
\text { mary therapeutic measures, the use of fibrinogen concentrate, cryoprecipitate, } \\
\text { or recombinant factor VIla can be considered (2C). }\end{array}$ & 7.3 & 1.5 \\
\hline
\end{tabular}

SD: standard deviation, MTP: massive transfusion protocol. 
sider," and "can be used" were applied to describe weak recommendations.

\section{Reviewing recommendations and producing a final proposal}

The draft recommendations prepared by the working committee were reviewed by the development committee to identify when the content of each recommendation overlapped, and, if necessary, to combine or modify the draft. Based on the revised recommendations, the final recommendations were confirmed after collecting opinions from trauma experts, experts from the Korean Society of Traumatology, and research method experts using the Delphi technique (Table 3).

\section{RESULTS}

\section{Does maintaining a low target blood pressure during initial fluid resuscitation improve the prognosis of trau- ma-induced hypovolemic shock patients?}

\section{Recommendations}

A. Restrictive volume replacement must be used for patients experiencing shock from trauma until hemostasis is achieved (1B).

B. The target systolic pressure for fluid resuscitation should be $80-90 \mathrm{mmHg}$ in hypovolemic shock patients (1C).

C. For patients with head trauma, the target systolic pressure for fluid resuscitation should be $100-110 \mathrm{mmHg}$ in hypovolemic shock patients (2C).

\section{Evidence summary}

Traditionally, maintaining a normal blood pressure range through fluid resuscitation was thought to allow the maintenance of blood flow to vital organs. However, a few studies have reported that in the initial stages of resuscitation, maintaining a lower blood pressure (permissive hypotension) through restrictive volume replacement led to an improved prognosis for trauma patients. The problem here is that the evidence is limited and restricted to studies done before hemostatic resuscitation was used. To further understand the efficiency of permissive hypotension, a guideline must be assembled from further studies. In the NICE guideline, two key studies were reviewed $[11,12]$. Bickell's study was limited to penetrative injuries, whereas Dutton reported on both penetrative and blunt trauma injuries. In Bickell's randomized prospective study of 598 patients, the group received prehospital permissive hypotension showed a significant difference in 30-day mortality and multiorgan failure rate, however the length of stay in the intensive care unit (ICU) did not differ between groups. In Dutton et al. [12] study with 110 randomized prospective patients, permissive hypotension did not significantly affect the 24-hour and 30-day death rates. In a combined analysis of the 708 patients in the two studies, permissive hypotension significantly decreased the rates of 24-hour mortality and 30-day mortality, but did not affect the length of stay in the ICU unit. In another randomized prospective study, 90 patients with shock and penetrative injuries were treated with two different target mean arterial pressures, $50 \mathrm{mmHg}$ and $65 \mathrm{mmHg}$, and the latter group showed higher rates of coagulation problems and higher 24-hour and 30-day death rates.

However, in a meta-study of 1,957 patients in multiple papers, restrictive volume replacement did not change the survival rate outcome [13]. Furthermore, permissive hypotension is contraindicated in patients with spinal or brain injuries due to the need to maintain adequate blood and oxygen flow in the central nervous system; for such patients, the treatment must focus on hemostasis efforts and stopping hemorrhage. For geriatric and high blood pressure patients, permissive hypotension treatment plans must be thoroughly considered. It was determined that the clinical practice guideline was acceptable and applicable in South Korea.

\section{Which type of fluid is appropriate for the initial treat- ment of traumatic hypovolemic shock patients?}

\section{Recommendation}

A. Isotonic crystalloid fluid is recommended for initially treating traumatic hypovolemic shock patients (1A).

\section{Evidence summary}

Although fluid replacement is used to maintain blood perfusion in tissue, there is no consensus on which type 
of fluid should be used. Accordingly, a prospective study compared the ratio of administered red blood cell (RBC) products and crystalloid fluid [14], and a randomized controlled trial (RCT) compared the properties and effects of different types of crystalloid fluids in a group of trauma patients [15]. A higher ratio of administered crystalloid fluid and RBC products was correlated with a significantly higher rate of multiple organ failure (odds ratio [OR], 2.6; 95\% confidence interval [CI], 1.2-5.4; $p=0.011$ ) and acute respiratory distress syndrome (ARDS; OR, 2.5; $95 \%$ CI, $1.2-4.9 ; p=0.010$ ). In another study, compared to Plasma-Lyte A, $0.9 \%$ saline showed more favorable results in terms of base deficit and magnesium levels, but did not yield a significant difference in the mortality rate and length of stay in the ICU. A 2013 meta-study cohort study concluded that colloid fluid resuscitation did not lower the mortality rate compared to crystalloid fluids, whereas hydroxyethyl starch increased the mortality rate [16]. In summary, colloid fluid is not only more expensive, but most importantly, does not improve the survival outcome of trauma patients and should not be used for fluid resuscitation.

It was determined that the recommendations on the type of fluid used for initial fluid resuscitation in the European guideline were acceptable and applicable in South Korea. However, the present guideline did not reflect the NICE guidelines' suggestion to restrict initial fluid administration and administer blood because the evidence is weak and emergency rooms in Korea are ill-equipped for emergency transfusions.

\section{Will raising the temperature of a hypothermic patient improve the survival outcomes of trauma patients with hypovolemic shock?}

\section{Recommendation}

A. Hypothermia should be prevented in patients with severe trauma, and if hypothermia occurs, the body temperature should be increased without delay (1B).

\section{Evidence summary}

A body temperature less than $35^{\circ} \mathrm{C}$ is correlated with platelet and coagulation dysfunction in severe trauma patients, causing a higher complication and death rate
[17-19]. In an analysis of the Pennsylvania Trauma Outcome Study, which contained 11,033 severe brain trauma patients, it was reported that low body temperature in the hospital caused an increase in the death rate [20]. To prevent hypothermia, it is recommended to remove the clothes of the patient and cover their body, increase the surrounding temperature, administer warm liquids, and (if severe) use an in vitro reheating apparatus [21,22].

It was determined that this clinical practice guideline was acceptable and applicable in South Korea. It is important to note that in South Korea, the importance of preventing hypothermia is often overlooked in the initial treatment of severe trauma patients, underscoring the need for an updated treatment guideline. Since there are no established guidelines for the treatment of hypothermia in traumatic head injury patients, no such guidelines were included.

\section{What is the appropriate treatment for acidemia in trau- ma patients with hypovolemic shock?}

\section{Recommendation}

A. Acidemia must be corrected with an appropriate means of treatment for hypovolemic trauma patients (1B).

\section{Evidence summary}

The main cause of acidemia is the reduction of perfusion, which has a harmful effect on coagulation [23]. Low ventilation and excessive administration of $\mathrm{NaCl}$ must be avoided [24]. Additionally, base excess is known to cause coagulation complications, resulting in a higher probability of complications and an increased death rate [23]. The threshold for base excess starts at -6 to -10 , and at a base excess of -15 , multiple coagulation factors are known to be reduced to half $[25,26]$. Raising the $\mathrm{pH}$ above 7.2 alone cannot improve coagulation factors, and it is meaningful to stop bleeding and replenish the coagulation factors [27]. Acidosis can become severe even when only a large number of RBCs are transfused [28], which reduces thrombin formation and promotes fibrinolysis [29]. It was determined that the clinical practice guideline was acceptable and applicable in South Korea. 


\section{What is the massive transfusion protocol (MTP) in trau- ma patients with hypovolemic shock?}

\section{Recommendations}

A. When a large amount of transfusion is required for trauma patients in hypovolemic shock, a massive transfusion protocol (MTP) should be used (1B).

B. The decision to implement MTP should be made based on hemodynamic status and initial responses to fluid resuscitation, not only the patient's initial condition (1B).

\section{Evidence summary}

To determine the use of MTP, the NICE guideline utilized nine retrospective studies comparing clinical risk scores, ABC scores, TASH scores, PWH scores, McLaughlin scores, emergency transfusion scores, the shock index, ATLS, and categories of shock. However, much is left to be desired in the study, as the proportion of missing data was very high in many studies, and the confidence interval was wide. One meta-analysis was conducted with $A B C$ scores, but the evidence level was not significantly high. In the studies of Brockamp et al. [30], Cotton et al. [31,32], Krumrei et al. [33], and Mitra et al. [34,35], ABC scores, systolic blood pressure, the presence of a penetration injury, blood pressure lower than $90 \mathrm{mmHg}$ and heart rate over 120 beats per minute at the arrival of the emergency ward, and FAST were measured to determine the use of MTP. In the Brockamp et al. [30] study, each indicator was compared by calculating the area under the curve (AUC) and determining a cut-off point. Although in a meta-analysis, the $\mathrm{ABC}$ score yielded a sensitivity of $72 \%$ and specificity of $88 \%$, the level of evidence leaves much to be desired [30-35]. Additionally, the methodology and evidence of other papers are questionable: Larson's test method was a single test, McLaughin's paper was based on only 3 months of analysis, and the Prince of Wales/ Rainer study also had low-quality evidence. In a study with 536 participants that analyzed the Revised Trauma Score, an AUC of 0.64 (0.59-0.69) was obtained [36]. Schreiber also showed a low level of evidence, and reported that three other papers using TASH scores had very low levels of evidence [30,37]. In the study of Dente et al. [38], it was reported that the patient group treated with
MTP, in a comparison with a group that received massive transfusion without a protocol, showed a higher survival rate and a lower rate of coagulation complications. It was determined that the clinical practice guideline was acceptable and applicable in South Korea.

\section{What ratio of concentrated red blood cells to fresh frozen plasma should be used for massive transfusion in traumatic hypovolemic shock patients?}

\section{Recommendation}

A. The ratio of plasma to red blood cell concentration should be at least 1:2 for trauma patients requiring massive transfusion (1B).

\section{Evidence summary}

In 680 trauma patients, the PROPPR study compared the effects of administering different ratios of fresh frozen plasma, platelets, and blood concentrations of 1:1:1 to 1:1:2 in a randomized controlled experiment [39]. The group that received a 1:1:1 ratio was reported to show significantly lower 24-hour and 30-day mortality rates. Although the risk of complications was not significantly higher in the 1:1:2 group than in the 1:1:1 group, the percentage of successful control of hemorrhage was significantly higher in the 1:1:1 group. Based on this study, the NICE guideline recommends using a 1:1:1 ratio. Although the European guideline reports that multiple studies had conflicting results and were affected by survival bias, the consensus is that a 1:1:1 ratio is appropriate and that the results of the PROPPR study are valid. However, unlike its US counterpart, the European guideline recommends a RBC to fresh frozen plasma ratio of 1:2 because some countries have difficulties in preparing platelets on time in the initial stages of MTP [40-45]. Furthermore, the European guideline considers correcting coagulopathy by administering fresh frozen plasma. As the Korean medical infrastructure lacks the preparation to dispatch platelets in a timely fashion in the early stages of resuscitation, it was determined that the European guideline would be more acceptable and applicable. 


\section{What are the criteria for administering vasopressors in trauma patients with hypovolemic shock?}

\section{Recommendation}

A. When a trauma patient is in life-threatening hypovolemic shock, vasopressors can be administered in addition to fluids and blood products (1B).

\section{Evidence summary}

When hypovolemia persists, vasopressors can be temporarily used to improve tissue perfusion. Not only do vasopressors help perfusion to the brain by maintaining the average arterial blood pressure in cases of severe head trauma, but it has also been reported in animal experiments that when homeostasis is not established, administering norepinephrine can help reduce the need for administering fluids and improve survival outcomes $[45,46]$. However, a limited amount of studies have investigated the effects of vasopressors on clinical trauma patients; furthermore, two such studies were retrospective studies with multiple limitations and low evidence levels [47]. In a clinical double-blinded controlled study of trauma patients with hypovolemic shock, administering low amounts of vasopressin during resuscitation resulted in a significantly lower need for administering fluid, but failed to improve survival outcomes significantly [48]. In conclusion, the use of vasopressors can help maintain tissue perfusion during fluid and blood transfusion for hypovolemic shock patients. However, it is important to note that the use of vasopressors for patients with cardiovascular problems must be carefully monitored due to the increased afterload of the heart. It was determined that the clinical practice guideline was acceptable and applicable in South Korea.

\section{Does the administration of tranexamic acid help hemo- stasis in trauma patients with hypovolemic shock?}

\section{Recommendation}

A. Early administration of tranexamic acid is recommended in trauma patients who are actively bleeding or at high risk of hemorrhage (1B).

\section{Evidence summary}

A 2015 Cochrane Review meta-analysis included three RCT studies: one about the effects of aprotinin, one about the effects of tranexamic acid in traumatic brain injury patients, and lastly the CRASH-2 trial [49-52]. The first RCT mentioned was excluded from consideration due to the small scale of the research. According to the CRASH-2 trial, patients injected with tranexamic acid had a lower mortality rate in a comparison of all-cause mortality $(1,463[14.5 \%]$ in the tranexamic acid group vs. $1,613[16.0 \%]$ in the placebo group; relative risk, 0.91; 95\% CI, 0.85-0.97; $p=0.0035$ ) [50]. Patients injected with tranexamic acid within 1 hour had a lower mortality rate from hemorrhage (198 of 3,747 [5.3\%] in the tranexamic acid group vs. 286 of 3,704 [7.7\%] in the placebo group; relative risk, 0.68 ; 95\% CI, 0.57-0.82; $p<0.0001$ ). For patients injected with tranexamic acid within 3 hours, the mortality rate from hemorrhage was also reduced (147 of 3,037 [4.8\%] vs. 184 of 2,996 [6.1\%]; relative risk: 0.79 ; 95\% CI, 0.64-0.97; $p=0.03$ ). However, the group that was given tranexamic acid after 3 hours showed a higher mortality rate (144 of 3,272 [4.4\%] vs. 103 of 3,362 [3.1\%]; relative risk, 1.44 ; 95\% CI, $1.12-1.84 ; p=0.004$ ) [51]. A 2015 meta-study reported that administering tranexamic acid as soon possible reduced the mortality rate of trauma patients. However, the report also reported that after 3 hours, administering tranexamic acid instead increased mortality rates. Furthermore, it was shown that for brain hemorrhage trauma patients, the effects of tranexamic acid are not conclusive, and the study reported that two relevant studies were underway [52].

Currently, in South Korea, tranexamic acid is routinely used. However, Korean medical law forbids the use of tranexamic acid during patient transportation unless a doctor is on-site. Therefore, the administration of tranexamic acid during transportation is not recommended.

\section{Other than blood products, what other therapies can be used in hypovolemic shock patients with traumatic coagulopathy?}

\section{Recommendation}

A. For traumatic hypovolemic patients with coagulopathy non-responsive to primary therapeutic measures, the use 
of fibrinogen concentrate, cryoprecipitate, or recombinant factor VIIa can be considered (2C).

\section{Evidence summary}

Fibrinogen is the last step in the coagulation cascade, acting as a ligand for platelet aggregation and factor activation $[53,54]$. Hypofibrinogenemia is a common finding in patients with massive hemorrhage. Low levels of fibrinogen in an acute hemorrhagic setting are correlated to a need for higher transfusion volume and mortality. In a prospective single-center study, patients with massive hemorrhage who were treated with fibrinogen concentrates showed a lower mortality rate and a higher 30-day survival rate [55]. However, there has been no further investigation through prospective trials or RCTs. Not only does desmopressin promote platelet adhesion to the vascular intima, but it is also the first-line treatment for bleeding in Von Willebrand disease patients. Additionally, desmopressin has been observed to improve the function of platelets in patients taking aspirin and clopidogrel. However, there has been no investigation of its use in trauma or brain injury patients.

Although European guidelines indicate the use of desmopressin for the treatment of hemorrhagic patients with Von Willebrand disease or for those who are taking antiplatelet agents, using desmopressin is contraindicated for hemorrhagic trauma patients. For those in whom treatment with other strategies fails and hemorrhage continues, recombinant factor VIIa can be considered. Serum levels of fibrinogen and platelets need to be stable within a given range for recombinant factor VIIa to be effective [56-58].

Since the function of coagulation enzymes can change in response to very slight differences in body temperature and $\mathrm{pH}$, body temperature and $\mathrm{pH}$ levels must be controlled before administration $[18,59,60]$. Although various studies have stated that the use of coagulation enzymes is beneficial in traumatic hemorrhage, there have been no significant large-scale investigations. In a double-blind RCT investigating the use of recombinant factor VIIa for blunt trauma, use the blood factor proved to decrease transfusion volume and the incidence of ARDS. However, the results failed to show statistical significance for penetration injuries [61].
Although fibrinogen concentrate and cryoprecipitate can be used in South Korea, recombinant factor VIIa is costly and not covered by the Korean national insurance policy. It must be used with caution.

\section{CONCLUSION}

This research was done to develop Korea's first clinical treatment guideline for trauma. Trauma-related specialists were the backbone for writing the recommendations by adapting multiple published guidelines in ways specific to Korea's medical infrastructure. The clinical treatment guideline for trauma will be revised with updated research every 5 years.

\section{ACKNOWLEDGEMENTS}

We thank to members of clinical research group for this study (Kang Hyun Lee, Seungje Go, Oh Snag Wown, Kim Seongyup, Dae Sung Ma, Jeong-Ho Yoon, Kyung-Hag Lee, Woo Jin Jung, Young Goun Jo, Cho Jae-Woo, Kang Kook Choi, Mi Young Choi, Jeong-Joo Hwang).

We are very grateful to 'Baek seung in' for translating this research.

\section{REFERENCES}

1. Jung KY, Kim JS, Kim Y. Problems in trauma care and preventable deaths. J Korean Soc Emerg Med 2001;12:45-56.

2. Cothren CC, Moore EE, Hedegaard HB, Meng K. Epidemiology of urban trauma deaths: a comprehensive reassessment 10 years later. World J Surg 2007;31:1507-11.

3. Davenport RA, Guerreiro M, Frith D, Rourke C, Platton S, Cohen $\mathrm{M}$, et al. Activated protein $\mathrm{C}$ drives the hyperfibrinolysis of acute traumatic coagulopathy. Anesthesiology 2017;126:115-27.

4. Brohi K, Singh J, Heron M, Coats T. Acute traumatic coagulopathy. J Trauma 2003;54:1127-30.

5. Khan S, Davenport R, Raza I, Glasgow S, De'Ath HD, Johansson $\mathrm{PI}$, et al. Damage control resuscitation using blood component therapy in standard doses has a limited effect on coagulopathy during trauma hemorrhage. Intensive Care Med 2015;41:239-47. 
6. MacLeod JB, Lynn M, McKenney MG, Cohn SM, Murtha M. Early coagulopathy predicts mortality in trauma. J Trauma 2003;55:39-44.

7. Maegele M, Lefering R, Yucel N, Tjardes T, Rixen D, Paffrath T, et al. Early coagulopathy in multiple injury: an analysis from the German Trauma Registry on 8724 patients. Injury 2007;38:298304.

8. Maegele M, Schöchl H, Cohen MJ. An update on the coagulopathy of trauma. Shock 2014;41(Suppl 1):21-5.

9. Martin M, Oh J, Currier H, Tai N, Beekley A, Eckert M, et al. An analysis of in-hospital deaths at a modern combat support hospital. J Trauma 2009;66(4 Suppl):S51-60; discussion S60-1.

10. Smith W, Williams A, Agudelo J, Shannon M, Morgan S, Stahel P, et al. Early predictors of mortality in hemodynamically unstable pelvis fractures. J Orthop Trauma 2007;21:31-7.

11. Bickell WH, Wall MJ Jr, Pepe PE, Martin RR, Ginger VF, Allen $\mathrm{MK}$, et al. Immediate versus delayed fluid resuscitation for hypotensive patients with penetrating torso injuries. N Engl J Med 1994;331:1105-9.

12. Dutton RP, Mackenzie CF, Scalea TM. Hypotensive resuscitation during active hemorrhage: impact on in-hospital mortality. J Trauma 2002;52:1141-6.

13. Kwan I, Bunn F, Roberts I; WHO Pre-Hospital Trauma Care Steering Committee. Timing and volume of fluid administration for patients with bleeding. Cochrane Database Syst Rev 2003;3:CD002245.

14. Neal MD, Hoffman MK, Cuschieri J, Minei JP, Maier RV, Harbrecht BG, et al. Crystalloid to packed red blood cell transfusion ratio in the massively transfused patient: when a little goes a long way. J Trauma Acute Care Surg 2012;72:892-8.

15. Young JB, Utter GH, Schermer CR, Galante JM, Phan HH, Yang Y, et al. Saline versus Plasma-Lyte A in initial resuscitation of trauma patients: a randomized trial. Ann Surg 2014;259:255-62.

16. Perel P, Roberts I, Ker K. Colloids versus crystalloids for fluid resuscitation in critically ill patients. Cochrane Database Syst Rev 2013;(2):CD000567.

17. Kutcher ME, Howard BM, Sperry JL, Hubbard AE, Decker AL, Cuschieri J, et al. Evolving beyond the vicious triad: differential mediation of traumatic coagulopathy by injury, shock, and resuscitation. J Trauma Acute Care Surg 2015;78:516-23.

18. Watts DD, Trask A, Soeken K, Perdue P, Dols S, Kaufmann C. Hypothermic coagulopathy in trauma: effect of varying levels of hypothermia on enzyme speed, platelet function, and fibrinolytic activity. J Trauma 1998;44:846-54.
19. Bernabei AF, Levison MA, Bender JS. The effects of hypothermia and injury severity on blood loss during trauma laparotomy. J Trauma 1992;33:835-9.

20. Rubiano AM, Sanchez AI, Estebanez G, Peitzman A, Sperry J, Puyana JC. The effect of admission spontaneous hypothermia on patients with severe traumatic brain injury. Injury 2013;44:1219-25.

21. Eddy VA, Morris JA Jr, Cullinane DC. Hypothermia, coagulopathy, and acidosis. Surg Clin North Am 2000;80:845-54.

22. Barthel ER, Pierce JR. Steady-state and time-dependent thermodynamic modeling of the effect of intravenous infusion of warm and cold fluids. J Trauma Acute Care Surg 2012;72:1590600 .

23. Lier H, Krep H, Schroeder S, Stuber F. Preconditions of hemostasis in trauma: a review. The influence of acidosis, hypocalcemia, anemia, and hypothermia on functional hemostasis in trauma. J Trauma 2008;65:951-60.

24. Beekley AC. Damage control resuscitation: a sensible approach to the exsanguinating surgical patient. Crit Care Med 2008;36(7 Suppl):S267-74.

25. Meng ZH, Wolberg AS, Monroe DM 3rd, Hoffman M. The effect of temperature and $\mathrm{pH}$ on the activity of factor VIIa: implications for the efficacy of high-dose factor VIIa in hypothermic and acidotic patients. J Trauma 2003;55:886-91.

26. Yücel N, Lefering R, Maegele M, Vorweg M, Tjardes T, Ruchholtz S, et al. Trauma associated severe hemorrhage (TASH)score: probability of mass transfusion as surrogate for life threatening hemorrhage after multiple trauma. J Trauma 2006;60:1228-36; discussion 1236-7.

27. Brohi K, Cohen MJ, Davenport RA. Acute coagulopathy of trauma: mechanism, identification and effect. Curr Opin Crit Care 2007;13:680-5.

28. Spahn DR, Rossaint R. Coagulopathy and blood component transfusion in trauma. Br J Anaesth 2005;95:130-9.

29. Martini WZ. Coagulopathy by hypothermia and acidosis: mechanisms of thrombin generation and fibrinogen availability. J Trauma 2009;67:202-8; discussion 208-9.

30. Brockamp T, Nienaber U, Mutschler M, Wafaisade A, Peiniger S, Lefering R, et al. Predicting on-going hemorrhage and transfusion requirement after severe trauma: a validation of six scoring systems and algorithms on the TraumaRegister DGU. Critical care 2012;16:R129.

31. Cotton BA, Gunter OL, Isbell J, Au BK, Robertson AM, Morris JA Jr, et al. Damage control hematology: the impact of a trauma 
exsanguination protocol on survival and blood product utilization. J Trauma 2008;64:1177-82; discussion 1182-3.

32. Cotton BA, Dossett LA, Haut ER, Shafi S, Nunez TC, Au BK, et al. Multicenter validation of a simplified score to predict massive transfusion in trauma. J Trauma 2010;69 Suppl 1:S33-9.

33. Krumrei NJ, Park MS, Cotton BA, Zielinski MD. Comparison of massive blood transfusion predictive models in the rural setting. J Trauma Acute Care Surg 2012;72:211-5.

34. Mitra B, Rainer TH, Cameron PA. Predicting massive blood transfusion using clinical scores post-trauma. Vox Sang 2012;102:324-30.

35. Mitra B, Mori A, Cameron PA, Fitzgerald M, Paul E, Street A. Fresh frozen plasma (FFP) use during massive blood transfusion in trauma resuscitation. Injury 2010;41:35-9.

36. McLaughlin DF, Niles SE, Salinas J, Perkins JG, Cox ED, Wade $\mathrm{CE}$, et al. A predictive model for massive transfusion in combat casualty patients. J Trauma 2008;64(2 Suppl):S57-63; discussion S63.

37. Vandromme MJ, Griffin RL, McGwin G Jr, Weinberg JA, Rue LW 3rd, Kerby JD. Prospective identification of patients at risk for massive transfusion: an imprecise endeavor. Am Surg 2011;77:155-61.

38. Dente CJ, Shaz BH, Nicholas JM, Harris RS, Wyrzykowski AD, Patel S, et al. Improvements in early mortality and coagulopathy are sustained better in patients with blunt trauma after institution of a massive transfusion protocol in a civilian level I trauma center. J Trauma 2009;66:1616-24.

39. Holcomb JB, Tilley BC, Baraniuk S, Fox EE, Wade CE, Podbielski JM, et al. Transfusion of plasma, platelets, and red blood cells in a $1: 1: 1$ vs a 1:1:2 ratio and mortality in patients with severe trauma: the PROPPR randomized clinical trial. JAMA 2015;313:471-82.

40. Ho AM-H, Dion PW, Yeung JH, Holcomb JB, Critchley LA, Ng CS, et al. Prevalence of survivor bias in observational studies on fresh frozen plasma:erythrocyte ratios in trauma requiring massive transfusion. Anesthesiology 2012;116:716-28.

41. Holcomb JB, Jenkins D, Rhee P, Johannigman J, Mahoney P, Mehta S, et al. Damage control resuscitation: directly addressing the early coagulopathy of trauma. J Trauma 2007;62:307-10.

42. Kelly JM, Callum JL, Rizoli SB. 1:1:1 - warranted or wasteful? Even where appropriate, high ratio transfusion protocols are costly: early transition to individualized care benefits patients and transfusion services. Expert Rev Hematol 2013;6:631-3.

43. Ketchum L, Hess JR, Hiippala S. Indications for early fresh fro- zen plasma, cryoprecipitate, and platelet transfusion in trauma. J Trauma 2006;60(6 Suppl):S51-8.

44. Snyder CW, Weinberg JA, McGwin G Jr, Melton SM, George RL, Reiff DA, et al. The relationship of blood product ratio to mortality: survival benefit or survival bias? J Trauma 2009;66:35862; discussion 362-4.

45. Gelman S, Mushlin PS. Catecholamine-induced changes in the splanchnic circulation affecting systemic hemodynamics. Anesthesiology 2004;100:434-9.

46. Poloujadoff MP, Borron SW, Amathieu R, Favret F, Camara MS, Lapostolle F, et al. Improved survival after resuscitation with norepinephrine in a murine model of uncontrolled hemorrhagic shock. Anesthesiology 2007;107:591-6.

47. Herrois A, Hamada SR, Duranteau J. Fluid resuscitation and vasopressors in severe trauma patients. Curr Opin Crit Care 2014;20:632-7.

48. Cohn SM, McCarthy J, Stewart RM, Jonas RB, Dent DL, Michalek JE. Impact of low-dose vasopressin on trauma outcome: prospective randomized study. World J Surg 2011;35:430-9.

49. Ker K, Roberts I, Shakur H, Coats TJ. Antifibrinolytic drugs for acute traumatic injury. Cochrane Database Syst Rev 2015;(5):CD004896.

50. CRASH-2 trial collaborators; Shakur H, Roberts I, Bautista R, Caballero J, Coats T, Dewan Y, et al. Effects of tranexamic acid on death, vascular occlusive events, and blood transfusion in trauma patients with significant haemorrhage (CRASH-2): a randomised, placebo-controlled trial. Lancet 2010;376:23-32.

51. CRASH-2 collaborators; Roberts I, Shakur H, Afolabi A, Brohi K, Coats T, Dewan Y, et al. The importance of early treatment with tranexamic acid in bleeding trauma patients: an exploratory analysis of the CRASH-2 randomised controlled trial. Lancet 2011;377:1096-101, 1101.e1-2.

52. Yutthakasemsunt S, Kittiwatanagul W, Piyavechvirat P, Thinkamrop B, Phuenpathom N, Lumbiganon P. Tranexamic acid for patients with traumatic brain injury: a randomized, double-blinded, placebo-controlled trial. BMC Emerg Med 2013;13:20.

53. Bombeli T, Spahn DR. Updates in perioperative coagulation: physiology and management of thromboembolism and haemorrhage. Br J Anaesth 2004;93:275-87.

54. Furie B, Furie BC. Mechanisms of thrombus formation. N Engl J Med 2008;359:938-49.

55. Shaz BH, Dente CJ, Nicholas J, MacLeod JB, Young AN, Easley K, et al. Increased number of coagulation products in relationship 
to red blood cell products transfused improves mortality in trauma patients. Transfusion 2010;50:493-500.

56. Sarode R, Milling TJ Jr, Refaai MA, Mangione A, Schneider A, Durn BL, et al. Efficacy and safety of a 4 -factor prothrombin complex concentrate in patients on vitamin $\mathrm{K}$ antagonists presenting with major bleeding: a randomized, plasma-controlled, phase IIIb study. Circulation 2013;128:1234-43.

57. Hoffman M. A cell-based model of coagulation and the role of factor VIIa. Blood Rev 2003;17 Suppl 1:S1-5.

58. Hoffman M, Monroe DM 3rd. A cell-based model of hemostasis. Thromb Haemost 2001;85:958-65.
59. Luna GK, Maier RV, Pavlin EG, Anardi D, Copass MK, Oreskovich MR. Incidence and effect of hypothermia in seriously injured patients. J Trauma 1987;27:1014-8.

60. DeLoughery TG. Coagulation defects in trauma patients: etiology, recognition, and therapy. Crit Care Clin 2004;20:13-24.

61. Boffard KD, Riou B, Warren B, Choong PI, Rizoli S, Rossaint R, et al. Recombinant factor VIIa as adjunctive therapy for bleeding control in severely injured trauma patients: two parallel randomized, placebo-controlled, double-blind clinical trials. J Trauma 2005;59:8-15; discussion 15-8. 